\title{
ENTRE O NADA E O ANÓDINO: PARÂMETROS, DIRETRIZES E A REFORMA DA EDUCAÇÃO NACIONAL
}

José Miguel Arias Neto*

Resumo: Este artigo tem por objetivo realizar uma crítica dos fundamentos dos Parâmetros Curriculares Nacionais tendo como referencia o conceitual da filosofia política que propõe um julgamento das ações humanas mediante as relações entre ética, moral e política.

Palavras-chave: Parâmetros Curriculares - Direitos Humanos Ética - Moral - Política.

A destruição do passado - ou melhor, dos mecanismos sociais que vinculam nossa experiência pessoal à das gerações passadas é um dos fenômenos mais característicos e lúgubres do final do século $X X$.

Eric Hobsbawm. Era dos Extremos

Uma reflexão sobre Parâmetros e Diretrizes Curriculares para o ensino fundamental e médio e para o ensino superior no Brasil coloca de imediato o seguinte problema: a partir de que perspectiva deve-se analisar estas questões?

Ora, em uma discussão sobre reformas da magnitude que se pretende com a implantação da nova LDB, é sobre os aspectos estruturais do sistema educacional que dever-se-ia refletir.

$\mathrm{Na}$ introdução de seu livro As morais da História (1991), Tzvetan Todorov estabelece distinções fundamentais entre as Ciências da Natureza e as Ciências Humanas, ou como eram antigamente denominadas, Ciências Morais e Políticas. A

\footnotetext{
* Professor do Departamento de História da Universidade Estadual de Londrina
} 
distinção entre as primeiras e as segundas reside na natureza do objeto:

Ora, justamente, nós não somos estranhos à nossa espécie nem poderíamos sê-lo. O próprio dessas ciências [humanas] é, assim, a identidade de natureza entre o seu sujeito e o seu objeto ou, dito de outra forma, o fato de esse objeto ser um ser humano. As ciências da Natureza, mesmo quando estudam o organismo humano, fazem-no como se se tratasse do da abelha ou do castor. As ciências do homem, essas, estudam o ser humano no que ele tem de propriamente humano. A grande diferença entre umas e outras, não está, portanto, no método (essas diferenças existem, mas não são decisivas) e sim na natureza do objeto estudado. (TODOROV, 1991, p.17)

Ainda de acordo com Todorov, esta diferença implica em algumas conseqüências que necessitam ser relacionadas: a) os seres humanos não são e não podem ser tratados como ratos de laboratórios; b) os seres humanos possuem uma liberdade inalienável e, portanto, apesar dos condicionamentos, não obedecem aos mesmos com regularidade, em outras palavras, são capazes de tomar iniciativas próprias, ou seja, são capazes de agir; c) a existência humana está impregnada de valores em todos os sentidos e, eliminar das ciências humanas qualquer relação aos valores é uma tarefa inumana. Deste modo pode-se considerar que as relações entre ética, moral e política constituem a problemática nuclear das ciências humanas. Embora ethos e mores tenham o mesmo significado (RICOEUR, 1995; CHAUÍ, 1998) - costumes - pode-se distinguir ética e moral. A ética diz respeito ao que é "estimado bom" e a moral àquilo que "se impõe como obrigatório" (RICOEUR, 1995, p. 161-2).

Quando se passa da ética à moral, adentra-se ao plano normativo. Este implica necessariamente na universalidade, pois trata-se da racionalização da ética. Kant exprimiu esta nos seus imperativos categóricos: 
1. Age unicamente segundo a máxima que faça com que possas querer, ao mesmo tempo, que ela se torne lei universal;

2. Age sempre de tal modo que trates a humanidade na tua própria pessoa e na de outro, não somente como um meio, mas sempre também como um fim em si. (Apud RICOEUR, 1995)

Ora, é exatamente porque Kant pressupõe que as relações entre os homens são de exploração e de violência, que ele introduz ao mesmo tempo a idéia de universalidade e da pessoa como fim em si. A moral assim é o interdito da violência e da exploração. No plano da justiça, isto redunda na idéia de equidade, que só pode resolver-se no âmbito da política (CHAUÍ, 1998).

Esta imagem do homem como sujeito universal, livre, racional e autônomo, proposta pela filosofia da ilustração, foi produto das grandes transformações ocorridas nos séculos XVIII e XIX e implicou em uma nova concepção da política e do Estado, fundada na noção de direitos humanos. Vários teóricos têm evidenciado como a emergência da noção de direitos representou a emergência de algo novo no campo da política, transformandoa radicalmente. Desta mutação emerge a representação de uma sociedade soberana e ao mesmo tempo dividida, posto que há o reconhecimento dos diversos modos de existência, de atividades, de comunicação, cujos efeitos são indeterminados, bem como a descoberta da transversalidade das relações sociais. Ocorre, portanto, a constituição de uma esfera pública - sociedade civil - espaço do desenrolar da trama dos negócios humanos.

Esta nova forma política tem como fundamento a indeterminabilidade, uma vez que indeterminada é a representação do homem que a constitui. É esta indeterminabilidade que caracteriza o Estado Democrático, para além do Estado de Direito e traça as linhas da política moderna: as lutas pela promoção dos direitos adquiridos e por novos sustentam-se em uma legitimidade cujos fundamentos encontram-se para além dos marcos legais tecidos pelo poder, 
ou melhor dizendo, em uma consciência dos direitos que engendra um poder social (LEFORT, 1983,69).

A questão atual, no entanto, como observa Norberto BOBBIO (1992), não é a de justificar os fundamentos dos direitos humanos, mas sim de efetivá-los, e isto depende fundamentalmente das prioridades estabelecidas, já que não é possível realizá-los de uma só vez. Daí a importância do debate público. Neste sentido, analisar-se-á a reforma educacional em curso a partir das seguintes indagações:

1) A proposta de reforma tem como fundamento a idéia de Direitos Humanos?

2) Isto significa perguntar: procura a reforma implantar um sistema educacional universal compreendendo o ser humano como finalidade em si?

Nos séculos XVIII e XIX, a instrução, originariamente um privilégio, passou a ser concebida como um dever e ao mesmo tempo, como educação nacional - meio para a formação do cidadão. No século XVIII, os revolucionários franceses - com sua pretensão de fundar uma nova pólis - recolocam a instrução pública - como elemento fundamental da Regeneração da Nação: na medida em que a Revolução suprime o Antigo Regime, cabe a ela também, fazer dos homens, cidadãos esclarecidos pela razão, indivíduos autônomos, princípio do mundo moderno. Daí a transformação, neste século e no seguinte, da instrução pública em Educação Nacional. Neste mesmo período a História constituise, como bem o demonstrou François Furet, em disciplina ensinável (ela adquire um método científico, uma concepção de evolução e um campo de estudos cronológico e espacial - a evolução nacional) e uma pedagogia do cidadão: "formar um cidadão compenetrado de seus deveres e um soldado que ama sua arma" - proclama Lavisse em 1890 (Apud. FURET, 1979). Também no Brasil do século XIX, a Educação era vista como o meio fundamental de formação do cidadão. Os políticos do Segundo Reinado expressaram esta convicção como se fosse, na expressão de Caetano Veloso, uma "verdade tropical". Em 
1835, Joaquim José Rodrigues Torres, o poderoso Visconde de Itaboraí, então presidente da província do Rio de Janeiro, referindo-se às Escolas de Primeiras Letras afirmava:

(...) os conhecimentos que aí se adquirem são indispensáveis não só para tratar dos negócios domésticos, mas ainda para bem desempenhar todos os deveres do cidadão. Fora uma tirania que o Estado impusesse aos seus membros obrigações sem lhes dar ao mesmo tempo meios de as bem conhecer e cumprir. (Apud MATOS, 1987, p.258).

É interessante notar que o ato da tirania do Estado não está na imposição de obrigações, mas sim de não dar meios aos homens de as conhecê-las. Daí a função da instrução. Mas não bastava aos homens conhecerem suas obrigações, era necessário que elas fossem entendidas como legítimas. Eis porque não bastava ao estado instruir, era necessário que ele educasse a todos: "É preciso (...) juntar à instrução primária a educação, e educar o povo, inspirar-lhe sentimentos de religião e moral, melhorando-lhe, assim pouco a pouco os costumes" afirmava Itaboraí em 1839, ao que Aureliano de Souza Coutinho acrescentaria em 1848: "(...) certas noções, certas práticas e sentimentos (...) devem ser gerais(...) É essa instrução comum, essa identidade de hábitos intelectuais e morais (...) que constituem a unidade e a nacionalidade. (Apud MATOS, 1987, p.258-264)

Assim, a Educação visava não somente à formação de um cidadão abstrato, mas do cidadão útil à Nação. Nada mais oposto às intenções éticas da ilustração (de emancipação do homem), do que a ideologia burguesa emergente que se funda na utilidade do trabalho e da produção. A educação nacional possui, portanto, uma conotação de adestramento para o trabalho, para a produção de bens a serem negociados no mercado e, porta nos seus pressupostos a condenação moral e a penalização do ócio (FOUCAULT, 1991).

É porque os homens são submetidos ao império das 
necessidades - (não há violência maior) que Marx denominou coação econômica - que eles se tornam servos da ordem despótica do capital. Individualizados pelas disciplinas são reincorporados como massa no âmbito da produção. Neste sentido a Educação possui uma dupla finalidade: a) promover o esquecimento da liberdade e b) produzir cidadãos úteis ao Estado e à Nação. Por isso mesmo a educação é concebida pelo Estado e pelas elites como dever e, ao contrário do que se possa imaginar, não visa a todos.

Uma análise da situação brasileira e dos projetos de reformas do ensino público atualmente em curso podem esclarecer esta última afirmação.

Inicie-se pela LDB. Marcia Angela AGUIAR (1996), observa que à primeira eleição de Fernando Henrique Cardoso, sucedeuse o bombardeamento, pelos aliados do novo governo, do antigo projeto de LDB - fruto de ampla discussão da sociedade brasileira, dando margem à emergência do projeto de Darcy Ribeiro, aprovado e sancionado em 1996. Na apresentação do texto, José Sarney observa que este instrumento jurídico era necessário para substituir a antiga lei, ultrapassada em virtude das mudanças ocorridas no Brasil e pelo novo enfoque que se dá à educação, "haja vista os rapidíssimos avanços no campo da ciência e da tecnologia". Era necessária a reforma pois "sabemos que a educação formal em todos os níveis é condição insprescindível para o desenvolvimento; a ciência e a tecnologia são decorrências naturais do fomento à educação. (In RIBEIRO, 1991) O que é surpreendente não é o fato da antiga LDB ser considerada ultrapassada, mas sim o fato de sê-lo porque as mudanças científicas e tecnológicas promoveram uma mudança nas concepções de educação. Esta exposição de motivos casa-se perfeitamente com o artigo 205 da Constituição, que afirma ser a educação direito de todos e dever do estado e da família, e que será promovida e incentivada com a colaboração da sociedade visando ao pleno desenvolvimento da pessoa, seu preparo para o exercício da cidadania e sua qualificação para o trabalho, bem como com o parágrafo segundo do artigo primeiro da própria 
LDB: a educação escolar deverá vincular-se ao mundo do trabalho e à justiça social.

Isto posto, é suficiente para se perceber que, ao contrário das declarações de direitos - nas quais o ser humano é reconhecido como possuindo um fim em si mesmo, aqui tratase de atar o conceito de humanidade e de cidadania à potencialidade produtiva da pessoa. Por isso mesmo, a LDB vincula a educação em primeiro lugar ao mundo do trabalho e em seguida à justiça social. É evidente que não se trata apenas de uma questão de ordem de exposição, mas sim da opção política do legislador. Permanece, portanto, a concepção da formação de cidadãos úteis dos quais espera-se um comportamento produtivo. Eis aí a diferença entre Estado de Direito e Estado Democrático, quando observado do ponto de vista da Educação Nacional. Como observa GRAMSCI (S/D, p.126):

(...) a tendência democrática, intrinsecamente não pode consistir apenas em que um operário manual se torne qualificado, mas em que cada 'cidadão' possa se tornar 'governante' e que a sociedade o coloque, ainda que 'abstratamente' nas condições gerais de poder fazê-lo: a democracia política tende a fazer coincidir governantes e governados (no sentido de governo com o consentimento dos governados), assegurando a cada governado a aprendizagem gratuita das capacidades e da preparação técnica geral necessárias ao fim de governar.

Assim, uma sociedade democrática deve preparar cidadãos capazes de tomar decisões - nos mais variados âmbitos da vida - de modo livre e autônomo ou, em outras palavras, capazes de agir ética e politicamente. Em consonância com a Constituição e com a LDB, os Parâmetros Curriculares para o ensino fundamental e médio, propõem a formação de um cidadão útil. Seria necessário dizer que nas leis brasileiras está implícita da idéia do cidadão inútil? E que todos nós tendemos a descartar 
o que consideramos inútil? Foi já afirmado que a escola proposta pelos Parâmetros é idealizada, distante da realidade brasileira e excludente (NEVES, 1998). De fato, os documentos dos Parâmetros são redigidos com o palavrório dos Direitos Humanos, da Pedagogia Moderna, etc.. etc. ... Mas repetem à exaustão princípios bem antiquados: o professor deve.....os alunos devem adquirir os seguintes comportamentos.....

Essa pobreza de espírito, essa miséria repetitiva, sem inspiração, sem criatividade e vulgar deve-se ao fato de que não há nada de objetivo a falar, a não ser que se deve preparar cidadãos produtivos. Ora, nesta medida os especialistas estão literalmente pouco se importando com os excluídos e com a escola. A reforma da educação não começa pela reforma do sistema educacional, pela qualificação e valorização do professor. A reforma da educação começa pela mudança dos conteúdos!

"From middle class to middle class". A arrogância - dos especialistas-middle class tupiniquins é esquizofrênica. Fala-se do Brasil? Para o Brasil? De que Brasil se fala? Não é decerto para aquele cuja distribuição de renda é a seguinte:

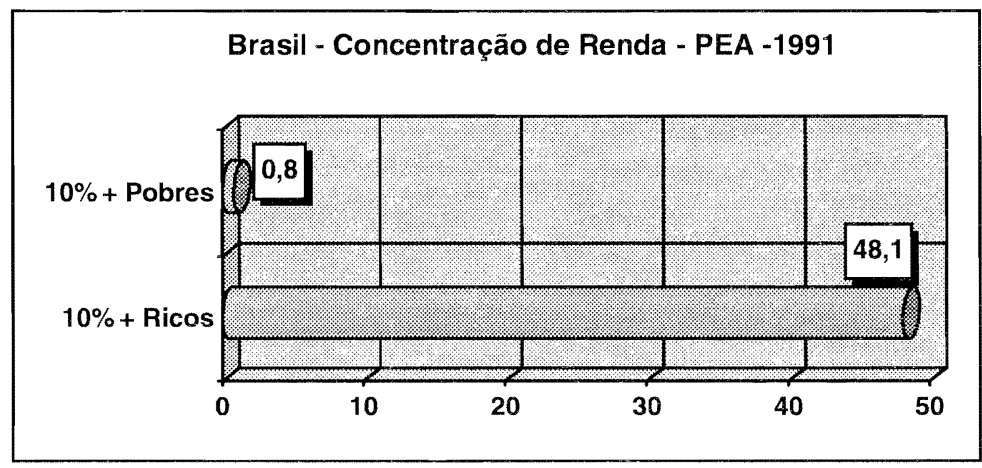

Fonte: Relatório brasileiro sobre desenvolvimento social. Estudos Avançados. São Paulo, v 9, n 24, p.16

A pobreza no Brasil atinge índices alarmantes. Em 1990 calculava-se que $12 \%$ da população (16,6 milhões) eram 
indigentes e 27\% ( 39,0 milhões) eram pobres. Indigente é aquele cuja renda não permite atender as necessidades básicas alimentares; pobre é aquele que cuja renda não permite atender as necessidades básicas de alimentação, moradia e vestuário (LAMPREA, 1995, p. 19).

Este quadro não se alterou muito ao longo da década. $O$ Relatório das Nações Unidas sobre desenvolvimento humano de 1997, caracteriza o Brasil como um país de desenvolvimento humano médio. Traçando um perfil da pobreza humana no país no período 1990-1995, o relatório demonstra que $14 \%$ da população não espera sobreviver aos 40 anos, 27\% não têm acesso à água potável, 16,7\% dos adultos são analfabetos, 30\% das crianças não atingem o $5^{\circ}$ ano de escolaridade e que o PIB real per capita é de US\$ 578 para os $20 \%$ mais pobres e de US\$ 18.563 para os $20 \%$ mais ricos(ONU, 1997, p. 54).

Talvez seja interessante para se ter uma visão de conjunto, verificar dados quanto ao desenvolvimento humano no Brasil de modo mais global. O conceito de desenvolvimento humano é muito amplo e variável, mas abrange essencialmente "o processo de alargamento da escolha das pessoas e o nível de bem-estar atingido" (ONU, 1997, p.14). Assim, para elaborar o IDH - Índice de Desenvolvimento Humano, são considerados "três dimensões básicas do desenvolvimento humano - a longevidade, o conhecimento e um padrão de vida adequado. Sendo um índice composto, o IDH contém assim três variáveis: esperança de vida, nível educacional (alfabetização de adultos e escolaridade conjunta nos ensinos primários, secundário e superior) e PIB real per capita." O IDH pode, portanto, servir de indicador da realização dos Direitos Humanos (civis e políticos, econômicos e sociais) de cada país, inclusive o educacional, que é o caso presente.

Para apreciar a situação brasileira no contexto internacional, apresentar-se-ão aqui os dados dispostos da seguinte forma: Mercosul (Argentina, Brasil, Paraguai e Uruguai), dois representantes da União Européia (os de índice mais alto França e mais baixo - Portugal) e dois representantes do NAFTA ( também os de índice mais alto - Canadá e mais baixo - México). 
Os dados são referentes ao ano de 1994, e destacam-se de um conjunto de 175 países analisados no Relatório.

\begin{tabular}{|c|c|c|c|c|c|c|}
\hline País & Ordem IDH & $\begin{array}{c}\text { Esperança } \\
\text { de vida ao } \\
\text { nascer } \\
\text { (anos) }\end{array}$ & $\begin{array}{c}\text { Taxa de } \\
\text { alfabet. De } \\
\text { adultos } \\
(\%)\end{array}$ & $\begin{array}{c}\text { Escolaridad } \\
\text { e Bruta } \\
1^{\circ}, 2^{\circ} \text { e } 3^{\circ} \\
\text { ciclos } \\
(\%) \\
\end{array}$ & $\begin{array}{l}\text { PIB real } \\
\text { per capita } \\
\text { (US\$) }\end{array}$ & $\begin{array}{l}\text { Valor do } \\
\text { IDH }\end{array}$ \\
\hline Canadá & 1 & 79,9 & 99,0 & 100 & 21.459 & 0,960 \\
\hline França & 2 & 78,7 & 99,0 & 89 & 20.510 & 0,946 \\
\hline Portugal & 31 & 74,6 & 89,6 & 81 & 12.326 & 0,890 \\
\hline Argentina & 36 & 72,4 & 96,0 & 77 & 8.937 & 0,884 \\
\hline Uruguai & 37 & 72,6 & 97,1 & 75 & 6.752 & 0,883 \\
\hline México & 50 & 72,0 & 89,2 & 66 & 7.384 & 0,853 \\
\hline Brasil & 68 & 66,4 & 82,7 & 72 & 5.362 & 0,783 \\
\hline Paraguai & 94 & 68,9 & 91,9 & 62 & 3.531 & 0,706 \\
\hline
\end{tabular}

Verifica-se que mesmo diante de países considerados em desenvolvimento e normalmente utilizados em termos de dados comparativos para a economia como a Argentina e o México, o IDH brasileiro é baixo, isto porque todas as taxas estão aquém dos países mencionados: a expectativa de vida, a alfabetização, a escolaridade bem como o PIB per capita. O dado mais significativo é que o Brasil, sob qualquer posição relativa que se queira analisar, está na contramão dos investimentos em Educação, em termos mundiais. Foi de fato o único país do grupo selecionado que diminuiu escandalosamente os investimentos públicos na Educação. Nestes anos o Brasil passou a fazer parte de um clube muito seleto e sinistro de 06 países (dos 175 analisados no Relatório) que investe menos de $2 \%$ do PNB na Educação:

\begin{tabular}{|l|c|c|c|}
\hline \multicolumn{4}{|c|}{ Despesa Pública na Educação em \% do PNB } \\
\hline Prasil & $\begin{array}{c}\text { Ordem do } \\
\text { IDH }\end{array}$ & $\mathbf{1 9 8 0}$ & $\mathbf{1 9 9 3 - 9 4}$ \\
\hline Indonésia & 68 & 3,6 & 1,6 \\
\hline El Salvador & 99 & 1,7 & 1,3 \\
\hline Guatemala & 112 & 3,9 & 1,6 \\
\hline Nigéria & 117 & 1,9 & 1,6 \\
\hline Haiti & 156 & 6,4 & 1,3 \\
\hline
\end{tabular}


Além disto, cabe destacar o que o Almanaque Abril de 1998 tece o seguinte comentário sobre os salários dos professores da rede pública de ensino no Brasil:

A qualidade de ensino depende muito da atuação dos professores. No entanto, os baixos salários pagos no país, desmotivam o professor, impedem investimentos em aperfeiçoamento profissional e obrigam a uma sobrecarga de trabalho. Além disso, há grandes discrepâncias salariais entre os estados: enquanto um professor com formação em magistério no estado da Paraíba recebe, em junho de 1997, $R \$ 104,00$ por uma carga horária de 40 horas semanais, no Distrito Federal recebe $R \$ 847,98$. Nos Estados Unidos, por exemplo, o salário de um professor com carga horária de 35 horas semanais é de US\$ 3 mil. (Almanaque Abril, 1998)

Pode-se concluir, portanto, o que é óbvio e vem sendo repetido há décadas: qualquer reforma educacional que objetivasse realmente uma educação pública Universal deveria ter começado pelos investimentos na estrutura educacional e pela valorização do profissional que nela atua.

É nesta situação depauperada, do país e da educação, que os Parâmetros Curriculares recaem, estabelecendo objetivos irreais. A escola se torna neste conjunto imaginário um espaço de produção de conhecimento, de aproximação e reelaboração do senso comum e do conhecimento histórico acadêmico, de conhecimento, análise e reelaboração do eu do outro e do nós, dos conflitos passados e presentes, das contradições sociais. $\mathrm{Na} 5^{\mathrm{a}}$ e $6^{\mathrm{a}}$ série o eixo temático é História das relações sociais, da cultura e do trabalho. Na $7^{\circ}$ e $8^{\circ}$ o eixo é História das representações e das relações de poder.

A qualquer historiador é evidente a inconsistência: somente na pobreza do espírito destes famosos especialistas é possível estudar de um lado a cultura ( $5^{\underline{a}}$ e $\left.6^{\circ}\right)$ e de outro as representações e as relações de poder $\left(7^{\circ}\right.$ e $\left.8^{\circ}\right)$. O saber histórico escolar como eles gostam de dizer - ata de um lado (nos objetivos) o eu 
- o outro - o nós e fragmenta de outro (no conteúdo) relação social/cultura e representação/relação de poder, como se fossem estágios cognitivos concretos. Quem vai contar aos professores o segredo da invenção da roda quadrada? Não fosse trágico, seria risível. No que diz respeito às orientações e técnicas didáticas, os especialistas sugerem que os professores trabalhem com vários livros, documentos, vídeos como se existisse de fato à disposição de toda escola e de todo professor uma profusão de livros, documentos, vídeos e outro materiais. Não bastasse isto, é sugerido que professores e alunos produzam documentos (vídeos, depoimentos orais etc.) visitem museus, exposições e sítios arqueológicos, como se não houvessem problemas econômicos e as escolas não carecessem de materiais elementares como quadro-negro e giz. A mesma visão transparece na caracterização da sociedade brasileira do ponto de vista de acesso aos bens de consumo tecnológicos:

no nosso cotidiano estamos constantemente nos beneficiando dos progressos da tecnologia sem, muitas vezes pensarmos sobre isso (...) praticamente em todas as casas brasileiras encontramos televisão, aparelhos de som e eletrodomésticos variados - indícios da presença da tecnologia na vida do homem moderno; e mais, as crianças já nascem imersas em um mundo informatizado: é comum vermos bebês apertando teclas em seus brinquedos para ouvir música e sons de animais; e as crianças pequenas brincando com sofisticados jogos eletrônicos assim como manipulando relógios digitais, máquinas de calcular, videocassetes microcomputadores com enorme naturalidade. (MEC - PARAMETROS CURRICULARES - INTRODUÇÃO, p. 60)

Definitivamente "from middle class to middle class". Os especialistas parecem desconhecer ou ignorar a situação dos meios de comunicação no Brasil: 


\begin{tabular}{|c|c|c|c|c|c|c|c|c|c|c|c|}
\hline \multicolumn{12}{|c|}{ PERFIL DA COMUNICACYÃO } \\
\hline País & $\begin{array}{c}\text { Recept. } \\
\text { de } \\
\text { Rádios } \\
\text { p/1000 } \\
\text { hab. }\end{array}$ & $\begin{array}{l}\text { Ap. de } \\
\text { Tv } \\
\text { P/ } 100 \\
\text { hab. } \\
\end{array}$ & $\begin{array}{c}\text { Títulos } \\
\text { de } \\
\text { livros } \\
\text { publ. } \\
\text { Pf } \\
100.00 \\
0 \\
\\
\\
1992 \\
94\end{array}$ & $\begin{array}{c}\text { Papel } \\
\text { de } \\
\text { escrita } \\
\text { e } \\
\text { impres. } \\
\text { Consu } \\
\text { mido( } \\
\text { tn } \\
\text { métrica } \\
\text { p/ } 1000 \\
\text { hab) } \\
1994\end{array}$ & $\begin{array}{c}\text { Est. De } \\
\text { Correio } \\
\mathrm{s} \\
\mathrm{P} / \\
100.00 \\
0 \\
\text { hab. } \\
\\
1991\end{array}$ & $\begin{array}{c}\text { Lintias } \\
\text { telefôn. } \\
\text { Princip } \\
\text { P/100 } \\
\text { hab. } \\
1994\end{array}$ & $\begin{array}{c}\text { Chama } \\
\text { d } \\
\text { Telef: } \\
\text { Interna } \\
\text { c. } \\
\text { Min. P/ } \\
\text { hab. }\end{array}$ & $\begin{array}{c}\text { Aparel. } \\
\text { De Fax } \\
\text { P/ } 100 \\
\text { hab. }\end{array}$ & $\begin{array}{c}\text { Assinat } \\
\text { de tel. } \\
\text { Celular } \\
\text { Pt } 100 \\
\text { hab. } \\
1992\end{array}$ & \begin{tabular}{|c|} 
Assinat \\
de \\
Interne \\
$t$ \\
P/ \\
10.000 \\
hab. \\
\\
1994
\end{tabular} & $\begin{array}{c}\text { PCs } \mathrm{p} f \\
100 \\
\text { hab. } \\
\end{array}$ \\
\hline Canadá & 1.051 & 65 & 76 & 96,3 & - & 59,0 & 28,3 & - & 6,5 & 352,7 & 17,5 \\
\hline França & 891 & 58 & 78 & 79,1 & - & 54,7 & 43,3 & 2,8 & 1,5 & 88,7 & 14,0 \\
\hline Portugal & 233 & 23 & 68 & 33,2 & - & 34,8 & 31,0 & - & 1,8 & 33,6 & 5,0 \\
\hline Argent. & 673 & 32 & 26 & 17,5 & - & 14,1 & 5,1 & 0,1 & 0,6 & 2,0 & 1,4 \\
\hline Uruguai & 606 & 52 & - & 13,7 & - & 18,4 & 14,6 & 0,3 & 0,2 & 3,0 & - \\
\hline México & 256 & 19 & - & 11,7 & - & 9,3 & 8,4 & - & 0,6 & 4,0 & 2,3 \\
\hline Brasil & 393 & 25 & 14 & 11,6 & 7,9 & 7,4 & 1,1 & - & 0,4 & 0,3 & 0,9 \\
\hline Parag. & 172 & 7 & 3 & 6,9 & 7,2 & 3,1 & 3,3 & - & 0,3 & - & - \\
\hline
\end{tabular}

Pelos dados acima apresentados, os brasileiros deveriam ficar satisfeitos de possuírem mais rádios e tvs que os portugueses, mexicanos e paraguaios, não fosse o incômodo fato de que nestes países há um número maior de computadores, mais pessoas possuem acesso à Internet e linhas telefônicas, além, é claro de que, - à exceção do México e do Uruguai acerca dos quais não se possuem dados - mais pessoas têm acesso a um número maior de livros.

Se considera-se que "praticamente todos" possuem em suas casas eletrodomésticos, vídeos etc... é porque a visão de mundo não vai além do plano piloto de Brasília, do eixo PerdizesPinheiros, ou do circuito Flamengo-Leblon. "Carapicuíba? Taguatinga? Nova Iguaçu? Quixeramobim? A cuma é?" Conheço 
não!!! Fica onde? No Japão, é?". E por falar em todos possuírem, o Almanaque Abril diz o seguinte:

"Recursos pedagógicos - Levantamento realizado nas escolas públicas em 1995, pelo Sistema de Avaliação do Ensino Básico (SAEB), relaciona o estado de conservação das escolas e seus recursos pedagógicos. Segundo a pesquisa, há crescimento do acesso aos recursos básicos, tais como quadro-negro, livros e bibliotecas. $O$ acesso a laboratórios e computadores é ainda reduzido: apenas $18,9 \%$ dos alunos da $4^{\circ}$ série do ensino fundamental estudam em escolas que possuem laboratório de ciências e 20,2\% em escolas com computador. E há grandes diferenças regionais quanto à distribuição de recursos: no norte e nordeste apenas $8,1 \%$ dos alunos estudam em escolas com laboratório de ciências, no sudeste este número sobe para $27,8 \%$; em relação ao computador, enquanto no norte no nordeste $14 \%$ dos alunos estudam em escolas com esse recurso, no sudeste o número sobe para $23,5 \% "$. (Almanaque Abril, 1998)

Parodiando Maria Antonieta, os especialistas bem poderiam dizer: "Não tem giz, que usem computadores!". Assim, os indigentes e os pobres - a grande massa de excluídos dos circuitos de produção e consumo, são excluídos também do universo cultural e da boa consciência do especialista que enuncia a reforma. Estamos no campo dos direitos negados e da violência de Estado.

O "balaio de bobagens/conteúdos programáticos" e as "orientações e métodos didáticos", propostos para o ensino de história pelos PCNs torna legitima esta situação de exclusão e violência, ou seja, contribui para a manutenção do status quo. $\mathrm{Na}$ medida em que a exclusão, a violência, o desemprego, a pobreza, a segurança, bem como as lutas sociais são concebidos como objeto de estudo, são postos concreta e simbolicamente para fora da escola. Todos esses fenômenos ocorrem lá na 
sociedade-objeto. O aqui-da-escola é o espaço para estudá-los e "apreender a resolver os conflitos e contradições pelo diálogo".

A História ministrada a partir daqueles eixos temáticos arrasta a todos para o restrito universo do quotidiano e a um presente irredimível, aprisionador, totalitário. Não há saída: é preciso tornar-se cidadão útil, trabalhador, disciplinado, criativo o suficiente para responder às demandas dos novos brinquedos da produção capitalista: os computadores e toda a parafernália restante.

O aqui da escola sem conflitos que estuda os conflitos da sociedade-objeto só pode ser assim constituído com professoresobjetos e alunos-objetos: todos eles moldados agora à nova política de inserção do Brasil no mercado mundial. Assim o objetivo da escola é moldar o novo instrumento do qual o capitalismo nacional precisa: um trabalhador renovado, porque as máquinas atuais são mais complexas e suas extensões assim o devem ser também.

Daí toda esta linguagem "middle class" dos documentos: a educação continua a ser um privilégio! $O$ privilégio daqueles que potencialmente poderão ser aproveitados pelo mercado de trabalho. O resto.....Ah! o resto....o resto vai para a correção de fluxo porque o Banco Mundial exige melhores índices educacionais para o Brasil e, obviamente não fica bem ao país exibir taxas elevadas de analfabetismo, de repetência e de evasão escolar. O funcionalismo público é responsável pela crise do estado, os professores são responsáveis pela crise na educação. Alguma coisa eles estão fazendo de errado. O fracasso escolar nada tem a ver com as condições sócio-econômicas do país, nem com o patrimonialismo e com a corrupção do Estado e, muito menos com os baixos investimentos no sistema. É o professor que não está cumprindo com sua obrigação!

Dizer que a Educação continua sendo um privilégio, implica afirmar que ela não é universal. O ensino de História nada mais é - para além de seu papel legitimador da situação presente do que técnica de manipulação, que visa produzir cidadãos úteis. Esta técnica tem um nome especial: saber histórico escolar. Dicotomia concebível pela fragmentação do mundo moderno, 
no qual a ciência perdeu seu caráter de busca da verdade para ser submetida ao critério da utilidade. A legitimidade da ciência no passado residia no fato de que ela poderia responder a questão do que é verdadeiro/ou falso ou do que é justo/ou injusto. Como observou Lyotard,

O Estado e/ou a empresa abandona o relato de legitimação idealista ou humanista para justificar a nova disputa: no discurso dos financiadores de hoje, a única disputa confiável é o poder. Não se compram cientistas, técnicos e aparelhos para saber a verdade, mas para aumentar o poder. (...) A relação entre a ciência e a técnica inverte-se (...) A questão (...) apresentada pelo estudante (....) pelo Estado ou pela instituição de ensino superior não é mais: isto é verdadeiro?, mas: para que serve isto? No contexto da mercantilização do saber, esta última questão significa comumente: isto é vendável? E, no contexto do aumento do poder: isto é eficaz? (LYOTARD, 1988, p. 92-3)

Considerado pelo lado da veiculação do saber, Lyotard considera que:

(...) a didática não consiste somente na transmissão de informação e que a competência, mesmo atuante, não se resume em ter boa memória de dados ou uma boa capacidade de acesso a memórias-máquinas.(...) Se o ensino deve assegurar não somente a reprodução das competências, como também seu progresso, seria preciso em conseqüência que a transmissão do saber não fosse limitada às de informações, mas que ela comporte a aprendizagem de todos os procedimentos capazes de melhorar a capacidade de conectar campos que a organização tradicional dos saberes isola ciosamente. A palavra de ordem da interdisciplinaridade (...) parece seguir esta direção. (...)A relação com o saber não é a da realização da vida do espírito ou da 
emancipação da humanidade; é dos utilizadores de um instrumental conceitual e material complexo e dos beneficiários de suas performances. (LYOTARD, 1988, p. 94)

Este também é o ponto de estrangulamento de toda a reforma universitária, não apenas no que diz respeito à questão dos conteúdos a serem ministrados (diretrizes curriculares) mas também no que toca à produção do conhecimento - a pesquisa.

O que salta à vista na própria LDB e nos pareceres do MEC é a idéia de utilidade do saber que torna imperativo à sobrevivência das Universidades a produção de um conhecimento e de um profissional úteis. Tomando como referência os documentos apresentados pelo MEC e por algumas universidades percebe-se claramente o conflito entre as tendências utilitarista e humanista. Pretendendo manter uma relação com o saber como realização da vida do espírito ou como emancipação da humanidade, as universidades insistem na formação de um profissional de História integral, nãofragmentado. Assim, as propostas das universidades são unânimes em procurar garantir: a) a autonomia universitária; b) a flexibilização dos currículos; c) a indissociabilidade entre ensino e pesquisa e, portanto, d) o não desvinculo na formação do Licenciado e do Bacharel. As disjunções e/ou desacordos dizem respeito à duração mínima bem como aos conteúdos essenciais. Há também uma preocupação em formar um profissional mais preparado para atender as demandas do mundo moderno.

Não obstante, o legislador, instituiu um outro caminho para a formação superior de profissionais: trata-se dos cursos seqüenciais por campo de saber, estabelecidos pela LDB e alvo de análise pelo CNE através do Parecer 670/97 de 06 de novembro de 1997. É possível interpretar estes cursos seqüenciais de várias maneiras. Os pareceristas do CNE os vêm, é claro, do modo mais positivo, sugerindo que se trataria de uma das modalidades de formação continuada. Discutindo a noção de campos de saber, o parecer observa: 
(...) A definição do inciso I do art. 44, a de que eles terão diferentes níveis de abrangência, sugere que campos de saber podem constituir-se a partir de elementos de uma das áreas do conhecimento, de suas aplicações ou de áreas técnico-profissionais, como podem numa delas estar contidos. $O$ avanço do conhecimento contemporâneo pela vertente da intersdisciplinaridade, aliado ao caráter de flexibilidade e de convite à inovação presente na nova Lei, permitem - ou melhor recomendam - que ambas as interpretações sejam adotadas.(..) Os cursos seqüenciais podem servir aos interesses de todos os que, possuindo um certificado de conclusão de ensino médio, buscam ampliar ou atualizar, em variado grau de extensão ou profundidade, seus horizontes intelectuais em campos das humanidades ou das ciências, ou mesmo suas qualificações técnico-profissionais, freqüentando o ensino superior sem necessariamente ingressar num curso de graduação. Em qualquer circunstância, deve ter-se sempre presente que uma pessoa pode realizar vários cursos seqüenciais ao longo de sua vida. (CNE, Parecer 670/97, p. 7)

Se a reforma do ensino superior objetivasse a atualização de conhecimentos ou de melhoria de qualificação técnicoprofissional, não haveria porque se criar uma nova modalidade de formação superior: Bastaria que se ampliasse o investimento nos cursos de extensão e especialização. Mas não se trata disto:

A ausência de delineamento específico para a nova figura convida a inovações que atendam as demandas por ensino pós-médio e superior oriundas dos mais diferenciados setores sociais, abrindo avenidas para a indispensável diversificação de nosso ensino superior, permitindo que a expansão das vagas alcance, em médio prazo, índices de matrículas comparáveis aos de outros países da América Latina com desenvolvimento sócioeconômico similar ao brasileiro. (CNE, Parecer 670/97, p. 2) 
Está-se, portanto, diante de uma política que visa, a médio prazo, a formação massiva de profissionais de nível superior sem curso de graduação. É certo que os cursos seqüenciais não conferem um diploma por área de saber, mas sim um certificado do campo de saber adquirido. Mas como se observa no Parecer 776/97 de 03 de dezembro, também de 1997,

A nova $L D B$ (...) pôs termo à vinculação entre diploma e exercício profissional, estatuindo que os diplomas constituem-se em prova da formação recebida por seus titulares.(CNE, Parecer 776/97, p. 1)

É louvável a perspectiva da formação continuada, mas também fica claro que os cursos seqüenciais objetivam muito mais que isto: incorporar um grande números de técnicos de formação superior ao mercado de trabalho utilizando-se da estrutura do ensino superior existente, facilitando o ingresso de um número maior de pessoas às Universidades sem despender os gastos necessários à uma formação superior regular. $\mathrm{Na}$ medida em que permite também que as instituições confiram certificados de cursos seqüenciais com aproveitamento das disciplinas cursadas pelos alunos evadidos da graduação esta proposta parece configurar uma imensa "correção de fluxo" em nível superior.

Que se retome a questão de Lyotard: é vendável? É eficaz? Do ponto de vista do Estado e do Mercado a resposta é necessariamente positiva. Mas se retomando a perspectiva da ética e da moral humanista que concebe a pessoa humana como finalidade em si a resposta parece ser mais complicada. Isto porque quando se fala em cursos seqüenciais por campo de saber no Brasil, infelizmente, não se está falando do cidadão que, satisfeitas suas necessidades como ser humano, dirige-se à Universidade para fazer um curso de Humanidades, para satisfazer suas curiosidades verdadeiramente "desinteressadas" ou com um interesse universal pelas questões "humanas", ou daquele profissional - devidamente formado que deseja conhecer mais profundamente este ou aquele aspecto de sua especialidade 
mas se fala em responder a demanda de um mercado de trabalho em transformação sem os investimentos necessários ao preparo de profissionais realmente qualificados, sem gastos por parte do Estado ou dos investidores privados na implantação de novas graduações. Trata-se do condicionamento das mentes humanas para responder a este ou aquele estímulo que satisfaça o desenvolvimento do capitalismo. Como já foi demonstrado aqui, o Brasil em 1993/4 investia apenas 1,6\% do PNB em educação. Deste total, apenas $26 \%$ era aplicado no ensino superior (ONU, 1997, p.180).

É este o critério que tem norteado também os investimentos em pesquisa e pós-graduação. Lyotard observa:

Os setores de pesquisa que não podem pleitear sua contribuição, mesmo indireta, à otimização das performances do sistema, são abandonados pelos fluxos de créditos e fadados à obsolescência. O critério do bom desempenho é explicitamente invocado pelas administrações para justificar a recusa de apoiar este ou aquele centro de pesquisas. (LYOTARD, 1988, p. 85)

Do exposto pode-se concluir que não há - pelo menos há um século e meio - mudanças na perspectiva de governos, ministérios e educadores quanto à finalidade última da educação nacional - a saber - a formação de cidadãos úteis. Ao contrário do que se imagina, o ensino de História sempre procurou e procura - mediante as várias reformas, inclusive a atual condicionar o comportamento social de acordo com a finalidade última acima enunciada. Decorre disto que o ensino de História tem contribuído para a manutenção da "ordem estabelecida". Os especialistas que elaboraram os PCNs - se concebessem realmente a Educação como direito - teriam indicado e sugerido caminhos, que se estabelecem no plano político - para a superação das carências do sistema e teriam concebido as diversidades regionais não apenas em termos de "peculiaridades culturais" (que parece um outro nome para folclore), mas sim em termos de necessidades reais (salários, incentivos, programas 
para produção de material didático, ampliação de bibliotecas e laboratórios, condições de trabalho para os professores - significa concretamente - liberação de tempo para preparação de aulas, de materiais, para o acompanhamento real da correção de fluxos). Teriam partido da base: das discussões com os agentes educacionais e não de um confortável gabinete em Brasília. Certamente, se pensassem a educação como direito e não como privilégio não teriam dito àqueles que nem possuem quadro negro e giz que o uso de computadores e vídeos é indispensável a um bom ensino de História. Por outro lado, os "conteúdos propostos" não passam de um conjunto anódino de curiosidades que, ao se efetivarem impedirão na prática, tanto a formação de cidadãos úteis, como também que os excluídos tenham acesso a conhecimentos relevantes que possibilitem a aquisição de uma linguagem mais elaborada e uma visão mais universal que ultrapasse as fronteiras da alienação a eles imposta. Não creio que saber as razões do uso de mini saia contribua para melhorar a vida de ninguém, mas uma boa aula sobre as Grandes Navegações, sobre a Segunda Guerra Mundial ou sobre a abolição da escravidão no Brasil pode realmente contribuir para o processo de formação de cidadãos - sem adjetivos. Na medida que se formem cidadãos, estes serão críticos e criativos e poderão decidir quando, onde e como interferir, seja no processo político, seja no processo produtivo.

Os Parâmetros Curriculares impostos pelos especialistas consideram as pessoas como meio para o aprimoramento do processo de acúmulo de capital, e, nesta medida reificam a exclusão e a violência. Assim, retomando o pressuposto inicial de que os seres humanos são capazes de agir - de iniciar algo novo no mundo - a minha proposta é atuemos contra os PCNs: 1) na medida que os "conteúdos são sugestões" como enfatizam os especialistas, eles devem - da forma como estão - ser definitivamente rejeitados; 2) cada professor, em conjunto com seus alunos e com a comunidade decidam o que ser ensinado e como; 3) que como critério de uniformidade mínima se mantenham os conteúdos tradicionais que não são os melhores, mas são melhores que o nada alienante dos PCNs. 
Já no que diz respeito à reforma Universitária os especialistas que elaborarão as DCNs deverão estar atentos a estes aspectos. Um ótimo sinal foi quererem ouvir a comunidade dos historiadores. É desejável que a reunião de Brasília produza mais que um documento dizendo o que se espera de professores e alunos. É necessário que os objetivos gerais do ensino e as condições do sistema sejam o ponto de partida para a concretização de um projeto de ensino superior que atenda as necessidades de qualificação do profissional de História sem perder o sentido da Universalidade da formação do Historiador. Necessário também que se dê aos cursos seqüenciais - através de uma regulamentação clara - a dimensão de formação continuada e não de correção ampliada de fluxo, como já foi aqui sugerido.

Rio de Janeiro/Londrina - Primavera de 1998

\section{Agradecimentos}

Meus agradecimentos aos professores Claudiomar dos Reis Gonçalves, Maria de Lourdes Mônaco Janotti, Pedro Paulo Abreu Funari, Armando Alves Filho, Silvia Lara, Margareth Rago, Kátia Marcelina de Souza, José Donizetti B. Oliveira, Luís Fernando Cerri e Sidnei J. Munhoz pela leitura e comentários críticos a este texto.

Abstract: This article objective build a critical of National Curriculum of History for Elementary and High School, having by reference concepts from Political Phylosophy that propose a judgement of humans actions according to relationships among Ethics, Moral and Politics.

Key-words: National Curriculum - Human Rights - Ethics - Moral - Politics. 


\section{Referências documentais e bibliográficas}

Fontes impressas:

MEC: Parecer 670/97 de 06.11.97 sobre cursos seqüenciais no ensino superior. Parecer $776 / 97$ de 03.12.97 que dá orientações para a elaboração de diretrizes curriculares dos cursos de graduação. Edital 4/97 de 03.12 .97 convocando as IES a apresentar propostas de diretrizes curriculares dos cursos superiores que serão elaboradas por uma Comissão de Especialistas. Parâmetros curriculares nacionais: terceiro e quarto ciclos do ensino fundamental - História. Parâmetros curriculares nacionais. Introdução (versão preliminar).

Propostas de Diretrizes Curriculares das seguintes Universidades: UFOP - Ouro Preto, UFJF- Juiz de Fora, UFMG - Minas Gerais, UFRS - Rio Grande do Sul, Unisinos Universidade do Vale do Rio dos Sinos, Rio Grande do Sul, UFF - Federal Fluminense. No Paraná existem dois documentos: um assinado pela UFPR - Curitiba e UEPG - Ponta Grossa; o outro assinado pela UEL - Londrina, UEM - Maringá e FAFI de União da Vitória. REHB/UFJF - Relatório do Seminário Virtual promovido pela Revista Eletrônica de História do Brasil da Rede Clionet Universidade Federal de Juiz de Fora.

\section{Bibliografia}

AGUIAR, Márcia A. Parâmetros curriculares nacionais e a formação do educador: a reforma brasileira em marcha. In Educação e Sociedade. Campinas, ano XVII, n 56, dezembro/ 96.

Almanaque Abril 98. CD-Rom. São Paulo: Abril Cultural, 1998. BOBBIO, Norberto. A era dos direitos. Rio de Janeiro: Campus, 1992.

CHAUÍ, Marilena. Ética e Violência. Texto apresentado no Coloquio Democracia e Liberdade: Interlocuções com Marilena Chauí. Departamento de História. Universidade Estadual de Londrina, 1998. 
FOUCAULT, Michel. Vigiar e punir. 9 ed. Petrópolis: Vozes, 1991. FURET, François. A oficina da História. Lisboa: Gradiva, s/d. (Original francês é de 1979).

GRAMSCI, Antonio. Os intelectuais e a organização da cultura. São Paulo: Círculo do Livro, s/d.

LAMPREA, Luiz Felipe. Relatório Brasileiro sobre desenvolvimento social. Estudos Avançados. São Paulo, v. 9 , n. 24, maio-agosto/95.

LEFORT, Claude. A invenção democrática: os limites do totalitarismo. 2 ed. São Paulo: Brasiliense, 1987.

LYOTARD, Jean-François. O pós-moderno. 3 ed. Rio de Janeiro: José Olympio, 1998.

MATOS, Ilmar. O tempo Saquarema. São Paulo: HUCITEC/INL, 1987.

NEVES, Joana. Proposta para parâmetros curriculares nacionais/ mec-área de História. Boletim da ANPUH. São Paulo, ano 6, n. 12 , março-junho/98.

ONU. Relatório do desenvolvimento humano: 1997. Lisboa: Trinova, 1997.

RIBEIRO, Darcy. Carta: falas, reflexões, memórias. Brasília: Gabinete do Senador Darcy Ribeiro, 1991.

RICOEUR, Paul. Em torno ao político. São Paulo: Loyola, 1995. TODOROV, Tzvetan. As morais da História. Lisboa: EuropaAmérica, s/d (Original francês é de 1991). 